\title{
Evaluasi Pelaksanaan Manajemen Patient Safety Di Ruangan Perawatan Rumah Sakit Umum Daerah Pangkep
}

\author{
Yasir Haskas ${ }^{1}$, Erna Kadrianti ${ }^{2}$, Victor H Rahantalin ${ }^{3}$ \\ ${ }^{1}$ STIKES Nani Hasanuddin Makassar \\ ${ }^{2}$ STIKES Nani Hasanuddin Makassar \\ ${ }^{3}$ STIKES Nani Hasanuddin Makassar
}

Alamat Korespondensi:(yasirhaskas@stikesnh.ac.id/085399690012)

\begin{abstract}
ABSTRAK
Keselamatan pasien (patient safety) merupakan suatu variabel untuk mengukur dan mengevaluasi kualitas pelayanan keperawatan yang berdampak terhadap pelayanan kesehatan. Tujuan dari penelitian ini ialah untuk mengevaluasi pelaksanaan keselamatan pasien di ruangan perawatan Rumah Sakit Umum Daerah Pangkep. Jenis penelitian yang digunakan ialah metode deskritif kuantitatif dengan teknik Observasional.Metode sampling yang digunakan adalah dengan teknik purposive sampling didapatkan sampling sebesar 73 responden sesuai degan kriteria inklusi. Pengumpulan data dilakukan dengan menggunakan lembar observasi. Hasil Penelitian evaluasi pelaksanaan manajemen keselamatan pasiendi ruangan perawatan Rumah sakit umum daerah Pangkep menunjukan bahwa dari 73 responden, yang telah melakukan identifikasi pasien yaitu sebanyak $73(100 \%)$ responden, komunikasi efektif $73(100 \%)$ responden, peningkatan keamanan obat sebanyak $54(76 \%)$ responden yang telah melakuka keamanan obat dan yang tidak melakuka 19 responden (24\%), ketepatan pasien tepat lokasi, tepat pasien, tepat operasi $73(100 \%)$ responden, pengurangan resiko infeksi $73(100 \%)$ responden, Pengurangan resiko pasien jatuh sebanyak 73 $(100 \%)$ responden. Kesimpulan dalam penelitian ini tentang patient safety dikatakan baik pada Ruangan Perawatan Rumah Sakit Umum Daerah Pangkep.
\end{abstract}

Kata kunci : Keselamatan Pasien, Enam Sasaran Keselamatan Pasien

\section{PENDAHULUAN}

Rumah sakit sebagai salah satu institusi pelayanan kesehatan memiliki fungsi penting dalam meningkatkan derajat kesehatan masyarakat sehingga dituntut untuk selalu meningkatkan mutu pelayanan yang diberikan (Pambudi,W., dkk. 2018).

Kualitas dan mutu pelayanan suatu rumah sakit sebagai intitusi yang menghasilkan produk teknologi jasa kesehatan sudah tentu tergantung juga pada kualitas pelayanan medis dan pelayanan keperawatan yang diberikan kepada pasien untuk meningkatkan mutu pelayanan kesehatan (Irawan, A.G,dkk.2017).

Patien Safety merupakan suatu sistem yang mencegah terjadinya Kejadian Tidak Diharapkan (KTD) akibat tindakan yang dilakukan atau bahkan tidak dilakukan oleh tenaga medis maupun non medis. Sistem tersebut meliputi: assessmen resiko, identifikasi dan pengelolaan hal yang berhubungan dengan resiko pasien, pelaporan dan analisis insiden, kemampuan belajar dari insiden dan tindak lanjutnya serta implementasi solusi untuk meminimalkan timbulnya resiko ( Pambudi, W., dkk. 2018).

Keselamatan pasien (patien safety) merupakan Isu global dan nasional, bagi rumah sakit memandang bahwa keselamatan merupakan hak bagi pasien dalam menerima pelayanan kesehatan dan komponen dari manajemen mutu. Keselamatan pasien dalam pelayanan kesehatan rumah sakit dimulai sejak tahun 2004 dan menjadi program kesehatan dunia oleh World Health Organization (WHO) yang didasarkan atas makin meningkatnya kejadian yang tidak diinginkan (Irawan, A.G,dkk.2017).

Di Indonesia gerakan patient safety diawali dengan membentuk komite keslamatan patient safety rumah sakit/KKPRS sebagai hasil raker Persatuan Rumah Sakit seluruh Indonesia (PERSI) Maret 2005 di Surabaya, diikuti dengan perancangan gerakan "patient safety rumah sakit. Keselamatan pasien merupaan salah satu komponen standar penelitian dalam akreditasi rumah sakit, diatur dalam Peraturan Mentri Kesehatan No.1691 tahun 2011. Keselamatan ,pasien dirumah sakit terdiri dari 6 sasaran meliputi : ketepatan identifikasi pasien, peningkatan komunikasi yang efektif, peningkatan keamanan obat yang diwaspadai, kepastian tepat lokasi, tepat prosedur, tepat pasien operasi, pengurangan resiko infeksi terkasit pelayanan kesehatan, pengurangan resiko jatuh.

Berdasarkan laporan diatas, data keselamatan pasien berdasarkan propinsi pada tahun 2007 di indonesia ditemukan 
tertinggi di propinsi DKI Jakarta yaitu 37,9\%, disusul propinsi Jawa Tengah 15,9\%, D.I Yogyakarta 13,8\%, Jawa Timur 11,7\%, Aceh $10,7 \%$, Sumatera Selatan $6,9 \%$, Jawa Barat $2,8 \%$, Bali $1,4 \%$, Sulawesi Selatan $0,7 \%$. Bidang spesialisasi unit kerja ditemukan paling banyak pada unit penyakit dalam, bedah, dan anak yaitu sebesar $56,7 \%$ dibandingkan unit kerja yang lain, sedangkan untuk pelaporan KNC lebih banyak dilaporkan sebesar $47,6 \%$ dibandingkan KTD sebesar 46,2\%. Namun data yang di temukan di Indonesia catatan kejadian yang terjadi dirumah sakit belum dikembangkan dengan keseluruhan, sehingga kejadian yang terjadi pada pasien dengan keselamatan pasien masi memiliki keterbatasan (Pambudi, W.,dkk. 2018).

Data Keselamatan Pasien dari Rekam Medis RSUD Pangkep pada bulan Juli sampai September 2018 didapatkan KNC: 20\% yang meliputi salah pemberian obat, dan salah pengambilan sampel darah. KPC: $10 \%$ meliputi salah pemberian hasil laboratorium.

Berdasarkan uraian latar belakang diatas maka penulis tertarik untuk melakukan penelitian tentang "Evaluasi Pelaksanaan Manajemen Patien Safety Di Ruangan Perawatan Rumah Sakit Umum Daerah Pangkep".

\section{BAHAN DAN METODE}

Lokasi, Populasi, Sampel

Penelitian ini dilaksanakan di Rumah Sakit Umum Daerah Pangkep, tanggal 12 s.d 31 Desember 2018 di ruangan perawatan. Populasi dalam penelitan ini adalah keseluruhan perawat diruang perawatan di RSUD Pangkep 2018. Populasi pada penelitian ini berjumlah 270 responden perawat.

1. Kriteria Inklusi

a. Responden yang tersedia berpartisipasi dalam penelitian

b. Perawat yang sedang aktif dalam pelayanan kesehatan.

c. Perawat yang sedang tidak memiliki masalah kedinasan.

2. Kriteria Ekslusi

a. Perawat yang sedang cuti.

b. Perawat yang sedang dalam keadaan sakit

\section{Pengumpulan Data}

1. Data Primer

Pengumpulan data primer dilakukan melalui metode observasi dan dengan menggunakan lembar observasional bersumber dari $\mathrm{JCl}$ (Joint Commission Internasional) terhadap para responden yang menjadi sampel. Lembar observasional menggali tentang pelaksanaan keselamatan pasien (patient safety) di RSUD Pangkep. Data primer yang lain diperoleh melalui observasi mengenai fasilitas dan perlengkapan keslamatan pasien di rumah sakit.

2. Data Sekunder

Data sekunder disebut juga data tangan kedua. Data sekunder adalah data yang diperoleh dari pihak lain, tidak langsung diperoleh oleh peneliti dari subjek penelitiannya. Biasa data dokumentasi atau laporan yang telah tersedia. Adapun data dari peneliti ini diperoleh dari bagian kepegawaian RSUD Pangkep

\section{Pengolahan Data}

1. Editing

Hasil wawancara angket, atau pengamatan dari lapangan harus dilakukan penyuntingan (editing) terlebih dahulu. Secara umum editing adalah merupakan kegiatan untuk pengecekan dan perbaikan isian formulir atau kuesioner.

2. Coding

Kuesioner semua setelah diedit atau disunting, selanjutnya dilakukan peng "kodean" atau "coding", yakni mengubah data berbentuk kalimat atau huruf menjadi data atau angka bilangan.

3. Entri data

Data entri adalah kegiatan memasukan data yang telah dikumpulkan ke dalam master tabel atau database komputer, kemudian membuat distribusi frekwensi sederhana atau bias juga dibuat tabel kontigensi.

\section{Analisa Data}

Analisa univariat digunakan untuk menjelaskan atau mendiskripsikan karakteristik setiap variabel yang diteliti. Pada analisa univariat ini data kategori dapat dijelaskan dengan angka atau nilai jumlah data presentase setiap kelompok

\section{HASIL PENELITIAN}

Tabel. 1 Distribusi Karakteristik Responden di RSUD Pangkep Tahun $2018(n=73)$

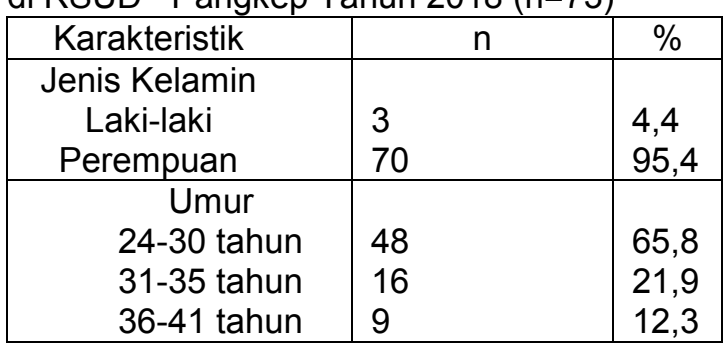




\begin{tabular}{|c|l|l|}
\hline $\begin{array}{c}\text { Pendidikan } \\
\text { Terakhir }\end{array}$ & & \\
DIII & 28 & 38,4 \\
S1 & 14 & 19,2 \\
Ners & 31 & 42,5 \\
\hline
\end{tabular}

Berdasarkan tabel 1, menunjukkan responden umumnya responden lebih banyak berjenis kelamin perempuan yaitu 70 responden $(95,4 \%)$, sedangkan yang berjenis kelaminlaki-laki $3(4,4 \%)$ responden.Untuk umur responden terbanyak 24-30 tahun yaitu $48(65,8 \%)$ responden, diikuti umur 31-35 yaitu $16(21,9 \%)$ responden dan berumur 3641 tahunyaitu $9 \quad(12,3 \%)$ responden. Sedangkan responden dengan pendidikan yang terbanyak yaitu Ners sebanyak 31 $(42,5 \%)$ responden, yang paling sedikit yaitu S1 sebanyak $14(19,2 \%)$ responden.

Tabel. 2 Distribusi Pasien, komunikasi Efektif, Kepastian tepat Oprasi, tepat pasien, tepat oprasi, Pengurangan Infeksi dan Rsiko jatuh di ruangan perawatan RSUD Pangkep tahun 2018.

\begin{tabular}{|c|c|c|}
\hline $\begin{array}{l}\text { Identifikasi Pasien, } \\
\text { komunikasi Efektif, Kepastian } \\
\text { tepat Oprasi, tepat pasien, } \\
\text { tepat oprasi, Pengurangan } \\
\text { Infeksi dan Rsiko jatuh }\end{array}$ & $\mathrm{n}$ & $\%$ \\
\hline Dilakukan & 73 & 100 \\
\hline Tidak dilakukan & 0 & 0 \\
\hline Total & 73 & 100 \\
\hline
\end{tabular}

Berdasarkan Tabel. 2 di atas, menunjukkan dari $73(100 \%)$ responden untuk melakukan Identifikasi Pasien, komunikasi Efektif, Kepastian tepat Oprasi, tepat pasien, tepat oprasi, Pengurangan Infeksi dan Rsiko jatuh telah dijalankan dengan baik.

Tabel. 3. Distribusi responden berdasarkan Keamanan Obat di ruangan perawatan RSUD Pangkep tahun 2018.

\begin{tabular}{|c|c|c|}
\hline Keamanan Obat & $\mathrm{n}$ & $\%$ \\
\hline Dilakukan & 54 & 76 \\
\hline Tidak dilakuan & 19 & 24 \\
\hline Total & 73 & 100 \\
\hline
\end{tabular}

Berdasarkan Tabel. 3 di atas menunjukan bahwa dari keselurah sebanyak 73 responden menunjukkan bahwa 54(65,5\%) reponden untuk Keamanan Obat telah dijalankan dengan maksimal dan yang belum menjalankan dengan maksimal terdapat 19 (24\%) responden. Pada ruangan Perawatan RSUD Pangkep.

\section{PEMBAHASAN}

1. Identifikasi Pasien

Hasil penelitian pada tabel 2 tentang pelaksanaan keselamatan pasein, menunjukan bahwa identifikasi pasien sudah terlaksana dengan baik, hal ini diketahui bahwa dari 73 responden $(100 \%)$ menyatakan bahwa 73 responden $(100 \%)$ melakukan identifikasi pada pasien, dan responden yang tidak melakukan identifikasi pada pasien yaitu $0(0 \%)$ tidak ada.

Hal ini berdasarkan hasil yang telah dilakukan di RSUD Pangkep dan ditemukan bahwa pasien diidentifikasi menggunakan gelang identitas, warna gelang disesuaikan dengan kondisi pasien, dimana gelang warna pink untuk perempuan, biru untuk laki-laki, warna merah untuk pasien elergi, warna ungu untuk pasien yang tidak boleh diresisutasi, dan warna kuning untuk pasien resiko jatuh.

Pada gelang identifikasi pasien tercantum nama lengkap pasien, tanggal lahir pasien serta nomor rekam medis, gelang identitas tersebut dipasangkan sejak awal pasien masuk yaitu di ruangan IGD hingga keluar dari rumah sakit dengan tujuan agar dapat membedakan antara pasien satu dengan pasien yang lain. Sehingga perawat akan memberikan tindakan terhadap pasien baik itu memberikan obat, menggambil darah, pemesangan infus serta peeriksaan maupun pemberian perawatan lainya. Perawat tersebut telah memeriksa dan mempersamakan data dengan identitas pasien.

2. Komunikasi Efektif

Hasil penelitian yang didapatkan berdasarkan tabel 2 tentang pelaksanaan keselamatan pasien menunjukan bahwa dari 73 responden. Dari 73 responden $(100 \%)$ melakukan komunikasi efektif dan responden yang tidak melakukan komunikasi efektif yaitu $0(0 \%)$ tidak ada. Hal ini berdasarkan hasil observasi yang telah dilakukan di ruang perawatan RSUD pangkep, tentang komunikasi secara langsung dan komunikasi secara tidak langsung.

Komunikasi efektif secara langsung yaitu dengan secara lisan pada saat visite pada pasien antara perawat dan dokter yang dimana dokter memberikan instruksi atau kepada perawat yang kemudian ditulis secara lengkap di catatan perkembangan pasien, dan dibacakan kembali oleh penerima instruksi dalam hal ini perawat. 
Kemudian perintah atau instruksi diverifikasi kembali oleh yang memberikan perintah yakni dokter dengan cara memberikan tanda tangan di dicatatan perkembangan pasien.

Komunikasi efektif secara tidak langsung yaitu dengan secara lisan melalui via telepon yaitu antara perawat dengan dokter yang dimana dokter memberikan istruksi atau perintah kepada perawat ditulis secara lengkap dicatatan perkembangan pasien.

3. Keamanan Obat

Berdasarkan tabel 3 tentang pelaksanaan keselamatan pasien menunjukan bahwa keamanan obat yang perluh diwaspadai kura cng maksimal dimana $54 \quad(76 \%)$ responden telah melakukan dengan baik dan 19 (24\%) responden tidak menjalankan keamanan obat dengan baik.

Hal ini berdasarkan hasil observasi yang telah dilakukan di RSUD Pangkep ditemukan rumah sakit memiliki daftar obatobatan yang perlu diwaspadai (High Alert), namun obat tersebut hanya berada pada ruangan tertentu dan disimpan dalam lemari khusus dan di kunci, apabila digunakan harus diperiksa ulang. Akan tetapi didapatkan sebagian responden tidak memberikan stiker Hijau untuk obat lassa, stiker gambar api untuk bahan mudah terbakar dan stiker gambar air untuk bahan mudah menyebabkan iritasi belum dijalankan dengan maksimal.

Obat high alert dilakukan penanda dengan stiker berwarna merah dan diberi lebel dengan tulisan dengan nama obat yang jelas pada setiap penyimpanan. Sebagian besar obat-obatan hanya terdapat di ruangan apotek.

Petugas perawatan dalam setiap pemberian obat, perawat menerapkan prinsip tujuh benar antara lain benar pasien, benarobat, benar dosis, benar waktu, benar cara/rute pemberian, benar dokumentasi, dan benar informasi. Prosedur tersebut diterapkan agar lebih dapat meningkatkan keamanan obat dan tidak terjadi kejadian yang tidak diharapkan.

4. Kepastian Tepat Lokasi, Tepat Pasien, Prosedur Operasi.

Hasi penelitian yang didapatkan pada tabel 2 tentang pelaksanaan tepat lokasi, tepat pasien, tepat prosedur operasi sudah terleksana dengan baik dimana 73 (100\%) responden yang telah menjalnkan dengan baik, sedangkan yang tidak menjalankan kepastian tepat lokasi operasi, tepat pasien, tepat operasi $0(0 \%)$ responden. Tepat pasien yaitu pada saat pertama kali masuk ke ruangan operasi, perawat terlebih dahulu mengkonfirmasi data pasien serta jenis operasi yang akan dilakukan terhadap pasien tersebut seuai dengan checklist..

5. Mengurangi Resiko Infeksi

Hasil penelitian menunjukan bahwa pelaksanaan keselamatan pasien pada pengurangan resiko infeksi sudah terlaksana dengan cukup baik, berdasarkan tabel 2 dari 73 responden $(100 \%)$ menyatakan bahwa 73 responden (100\%) mengurangi resiko infeksi, dan juga dapat dilihat rumah sakit telah menerapkan hand hygiene berdasarkan penduan dari WHO,hal ini bias di jumpai setiap ruangan di temukan handrup yang menempel di dinding serta wastafel dan juga tersedia sabun cair.

Hal ini berdasarkan hasilobservasi yang telah dilakukan di RSUD Pangkep, dan di temukan bahwa seluruh pihak di rumah sakit telah menerapka program kebersihan tangan yang efektif. Cuci tangan pada saat: sebelum menyentuh pasien, sebelum melakukan tindakan aseptik, sebelum terkontaminasi dengan cairan tubuh pasien dan setelah melakukan tindakan-tindakan infasif, setelah menyetuh pasien, sebelum memulai tindakan, setelah menyentuh daerah sekitar pasien.

6. Resiko Pasien Jatuh

Hasil yangdidapatkan berdasarkan tabel 2 tentang resiko pasien jatuh sudah terlaksana dengan baik, hal ini diketahui dari 73 rresponden menyatakan bahwa 73 responden $(100 \%)$ mengurangi resiko pasien jatuh, dan responden yang tidak mengurangi resiko pasien jatuh yaitu, 0 $(0 \%)$ tidak ada. Hal ini berdasarkan hasil observasi yang telah dilakukan di RSUD Pangkep ditemukan bahwa rumah sakit telah menerapkan sebuah proses pangkajian awal mengenai resiko pasien jatuh dan melakukan pengkajian ulang pada pasien bila ditunjukan ada perubahan kondisi atau pengobatan, selanjutnya akan diimplementasikan untuk mengurasi resiko jatuh jatuh bagi pasien yang dinilai beresiko.

Pasien yang dinilai beresiko akan dipasangkan gelang resiko jatuh yang berwarna kuning. Rumah sakit sangat memperhatiakan hal yang dapat menyebabkan pasien jatuh seperti memperhatikan lantai yang lincin akan dipasangkan tanda peringatan bahwa lantai tersebut licin agar dapat berhati-hati 
jika melewati area tersebut, setiap tempat tidur sudah mempunyai pengaman agar pasien tidak, memastiakan roda tempat tidur terkunci serta tempat tidur yang tidak terlalu tinggi, pencahayaan dalam ruangan yang cukup, memberikan edukasi kepada keluarga kepada pasien mengenai teknik pencegahan pasien jatuh.

\section{KESIMPULAN}

1. Ketepatan keselamatan pasien pada identifikasi pasien sudah terlaksana dengan baik.

2. Meningkatkan komunikasi efektif Pelaksanaan keselamatan pasien pada peningkatan komunikasi efektif sudah terlakana dngan baik.

3. Meningkatkan keamanan obat yang perlu diwaspadai Pelaksanaan keselamatan pasien pada peningkatan pada obat yang perlu diwaspadai sudah terlaksana dengan baik, namun masih terdapat sebagian kecil responden yang belum menjalankan dengan baik.

4. Memastikan tepat lokasi, tepat pasien, tepat prosedur operasi pelaksanaan keselamatan pasien pada kepastian tepat lokasi, tepat pasien, tepat prosedur sudah dilaksanakan dengan baik.

5. Pelaksanaan keselamatan pasien pada pengurangan resiko infeksi sudah terlaksana dengan baik.

6. Pelaksanaan keselamatan pasien pada resiko pasien jatuhterlasana dengan baik.

\section{SARAN}

1. Pimpinan/direkxi dan staf di rumah sakit untuk menjadikan penerapan keselamatan pasien di ruangan perawatan dapat menjadi prioritas, dan pertahankan apa yang sudah dijalankan dan dicapai dalam pelaksanaan enam sasaran keselamatan pasien di RSUD Pangkep.

2. Peneliti selanjutnya diharapkan dapat melakukan penelitian dengan metode kualitatif agar hasil yang didapatkan lebih lengkap dan lebih tergali secara mendalam, dan diharapkan dapat melakukan penelitian mengenai insiden keselamatan pasien dengan mengukur karateristik lain yang belum diteliti.

\section{DAFTAR PUSTAKA}

Bawale, S, C., J. S. V Sinolungan., Revelino S. Hamel. (2013). Hubungan Pengetahuan Dan Sikap Perawat Dengan Pelaksanaan Keselamatan Pasien (PATIENT SAFETY) Di Ruang Rawat Inap RSUD Liun Kendage Tahuna. Volume 1. Nomor 1. Ejounal keperawatan (e-Kp). Agustus 2013.

Budiman. (2013). Metode Penelitian Kesehatan. Bandung. PT Refika Aditama.

Cheria, A \& Gebrekidan , (2013) Kepemimpinan dan manajemen keperawatan yogyakarta: Imperium

David Sinarta Ginting (2014). Hubungan Pengetahuan Da Kemampuan Perawat Dengan Penerapan Standar Joint Commission International Tentang Keselamatan Pasien Di Instalasi Gawat Darurat RSUP.H.ADAM MAIK Medan.

Harista, I,A., (2018). Evaluasi Pelaksanaan Keselamatan Pasien (Patient Safety) Di Rumah Sakit Umum Daerah Labuang Baji Makasar. Makasar: Stikes Nani Hasanuddin.

Hidayat, A,A,A. (2017). Metodologi Penelitian Keperawatan Dan Kesehatan. Jakarta. Selemba Medika.

Irawan, A. G., Yulia S., Muliyadi. (2017). Hubungan Superfisi Dengan Penerapan Budaya Keselamatan Pasien Di Ruang Rawat Inap Rumah Sakit XX. Volume 5, Nomor 1, Palembang 2017.

Keles A. W., G.D Kandou., Ch.R. Tilaar. (2015. Analisis Pelaksanaan Standar Sasaran Keselamtan Pasien Di Unit Gawat Darurat Di RSUD Dr. Sam Ratulangi Tandono Sesuai Dengan Akreditasi Rumah Sakit Versi 2012.

Nike S.I. Sumangkut., Erwin Kristanto., Jantje Pongoh. (2017). Evaluasi Penatalaksanaan Sasaran Keselamatan Pasien Di Rumah Sakit GMIM Kalaresponden Amurang.

Pambudi, Y. D. W., Ani Sutriningsih., Dudella Desnani F. Yasin. (2018). Factor-Faktor Yang Mempengaruhi Perawat Dalam Penerapan 6 SKP (Sasaran Keselamatan Pasien) Pada Akreditasi JCl (Joint Commission International) Di Ruang Rawat Inap Rumah Sakit Panti Waluya Malang. Volume 3, Nomor 1, Malang 2018.

Sujarweni. A., (2014). Metodologi Penelitian Keperawatan. Yogjakarta. Gava Media 